\title{
Spontaneous thrombosis of neonatal vein of Galen malformation
}

\author{
Case report
}

\author{
Parham Moftakhar, M.D., ${ }^{1}$ Moise Danielpour, M.D., ${ }^{1}$ Marcel Maya, M.D., ${ }^{2}$ \\ and Michael J. AleXander, M.D. ${ }^{1}$ \\ Departments of ${ }^{I}$ Neurosurgery and ${ }^{2}$ Imaging, Cedars-Sinai Medical Center, Los Angeles, California
}

\begin{abstract}
Vein of Galen malformations are rare congenital intracranial vascular malformations. Based on reports in the literature, spontaneous thrombosis or regression of these lesions is rare. Patients have variable outcomes from an asymptomatic course to death. The reasons behind spontaneous thrombosis are not entirely understood. Here the authors present a case of an infant diagnosed with a vein of Galen malformation in utero that subsequently went on to thrombose or regress. A review of the published cases on this phenomenon and the potential causality are discussed. (DOI: 10.3171/2009.8.FOCUSO9162)
\end{abstract}

KEY WORDS - vein of Galen malformation - spontaneous thrombosis - neonate

$\mathrm{V}$ EIN of Galen malformations are rare intracranial vascular malformations constituting $1 \%$ of all cerebral vascular malformations. ${ }^{10}$ Although first described by Steinheil ${ }^{28}$ as early as 1895 as a "varix aneurysm," it has only been recently in the era of advanced neuroimaging that there we have arrived at a more complete understanding of this complex embryological malformation. For example, Raybaud and colleagues ${ }^{25}$ recognized that the ectatic vein is in fact not the vein of Galen but the median prosencephalic vein of Markowski, the embryonic precursor of the vein of Galen.

Previously, neonatal VGMs had a uniformly dismal prognosis, especially among patients presenting with cardiac failure, in whom the published mortality rate was up to $80-90 \%$ in early reports..$^{14}$ Advances in endovascular tools and techniques have improved the prognosis in many of these patients

There are rare cases reported in infants in whom neither surgical nor endovascular therapy is necessary, with spontaneous thrombosis and resolution of the malformation. Here we report a case of an infant diagnosed with a VGM in utero who was approached with expectant medical management, and subsequently experienced spontaneous thrombosis or regression of the malformation. A review of the pediatric literature on this phenomenon is also presented.

Abbreviations used in this paper: $\mathrm{ECG}=$ electrocardiography; $\mathrm{VGM}=$ vein of Galen malformation.

\section{Case Report}

History. This female neonate was born by spontaneous vaginal delivery at 39 weeks' gestation with Apgar scores of 8 and 9 at 1 and 5 minutes, respectively, after birth. The mother was a 20 -year-old primigravida female with no family history of vascular malformations. A prenatal ultrasound obtained 1 month prior to the birth had demonstrated a $1.5 \times 2.0-\mathrm{cm}$ cystic intracranial mass in the midline, posterior to the circle of Willis, consistent with a VGM. No evidence of fetal distress, cardiac failure, or hydrops was noted. The pregnancy was complicated by maternal fevers and premature rupture of membranes for 16 hours.

Examination. Initially in the neonatal intensive care unit the infant was noted to have grunting and had an oxygen saturation of $85 \%$ on room air. She was placed on $1 \mathrm{~L}$ of $60 \%$ oxygen by nasal cannula, and she subsequently developed normal oxygen saturations. On physical examination the anterior fontanel was soft, open, and flat, and the scalp veins were nondilated. On auscultation she had a hyperdynamic heart with a Grade 2/6 systolic murmur at the lower left sternal border.

A postnatal ultrasound and contrast-enhanced CT scan confirmed the diagnosis of a VGM. On CT scanning, there was no evidence of edema, infarct, or calcification. The dilation measured $1.4 \mathrm{~cm}$ transversely by 1.1 $\mathrm{cm}$ craniocaudally. There was associated dilation of the straight, transverse, and posterior sagittal sinuses (Fig. 

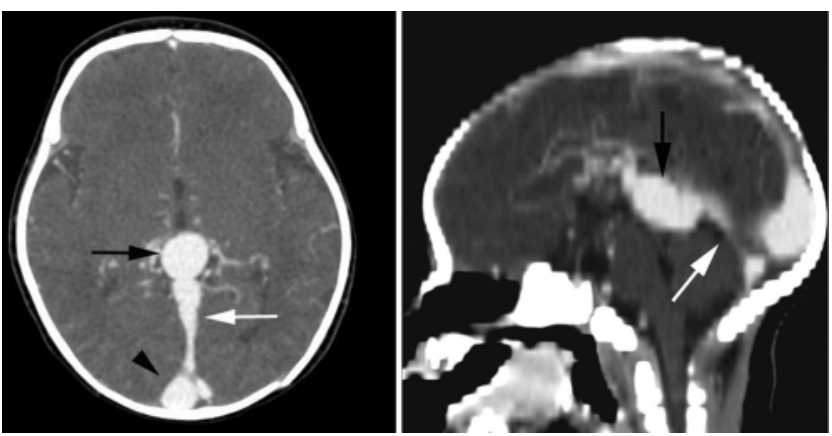

FIG. 1. Axial (left) and sagittal (right) reformatted contrast-enhanced CT scans demonstrating dilation of the persistent embryonic median prosencephalic vein of Markowski (vein of Galen) (black arrows), as well as dilation of the straight sinus (white arrows) and transverse/sagittal sinus confluence (arrowhead).

1). Multiple arterial feeders were noted from pericallosal, choroidal, and thalamoperforating arteries, consistent with the "choroidal" type of malformation (Fig. 2). A chest radiograph showed mild cardiomegaly with no evidence of congestive heart failure (Fig. 3). Cardiac ECG demonstrated reversal of blood flow at the aortic arch into the great vessels during diastole, consistent with cerebral arteriovenous shunting.

Follow-Up. Considering that the infant was neurologically asymptomatic and had no clinical evidence of significant heart failure, in that she did not require pharmaceutical intervention, endovascular therapy was postponed, and the patient underwent clinical followup. Although subsequent close clinical evaluation was recommended, the patient was lost to follow-up until 20 months of age.

At last follow-up, at 20 months of age, the child was

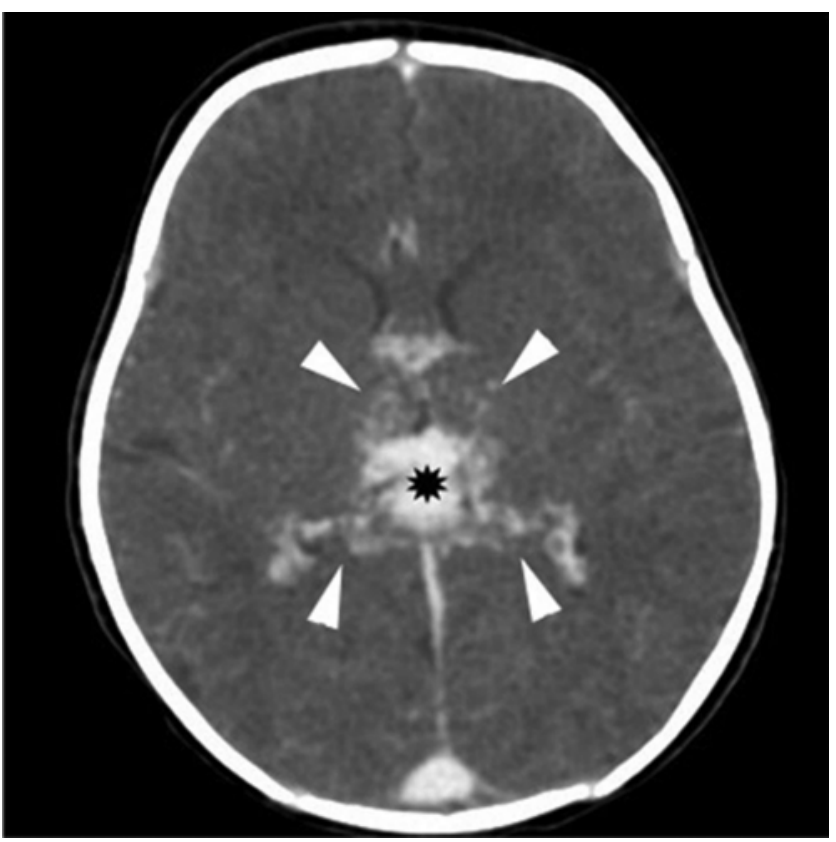

FIG. 2. Axial contrast-enhanced CT scan showing multiple choroidal and thalamoperforating arterial feeders (arrowheads) to the dilated vein (asterisk), characteristic of the choroidal-type VGM.

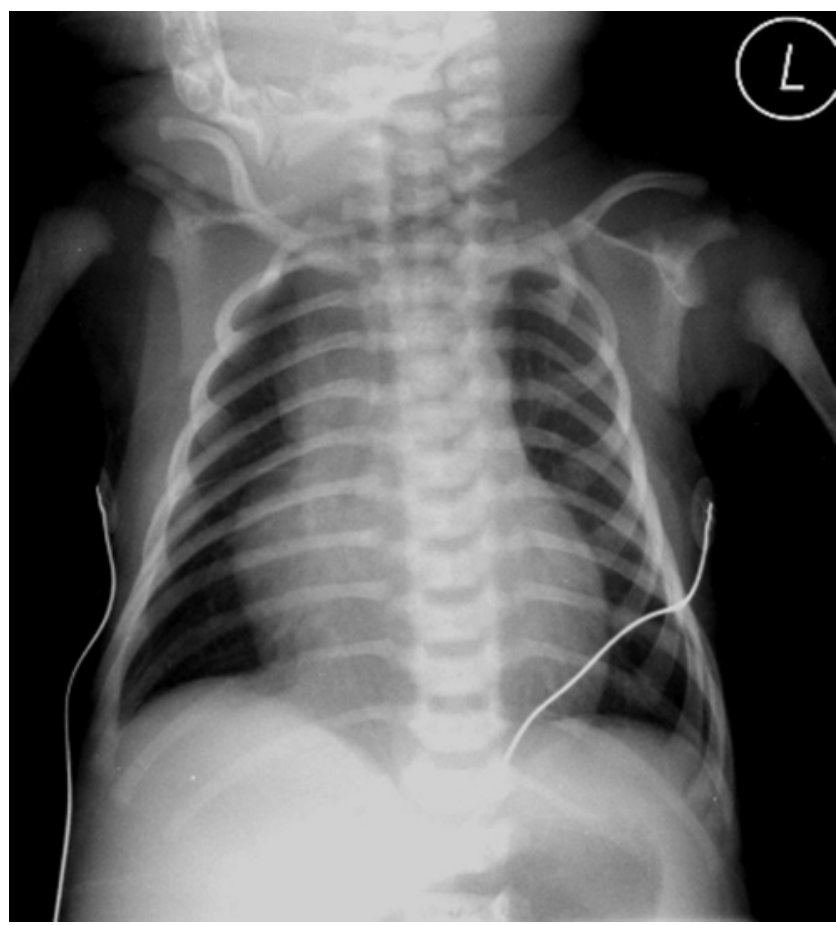

FIG. 3. Chest radiograph revealing mild cardiac and mediastinal enlargement, without pulmonary findings of congestive heart failure.

doing well without any cardiac or neurological complications. Developmentally she was meeting all her milestones, including running and putting words together. On MR imaging and MR venography, the previously diagnosed VGM had apparently spontaneously thrombosed or regressed, with no dilated vein of Galen and no pro-

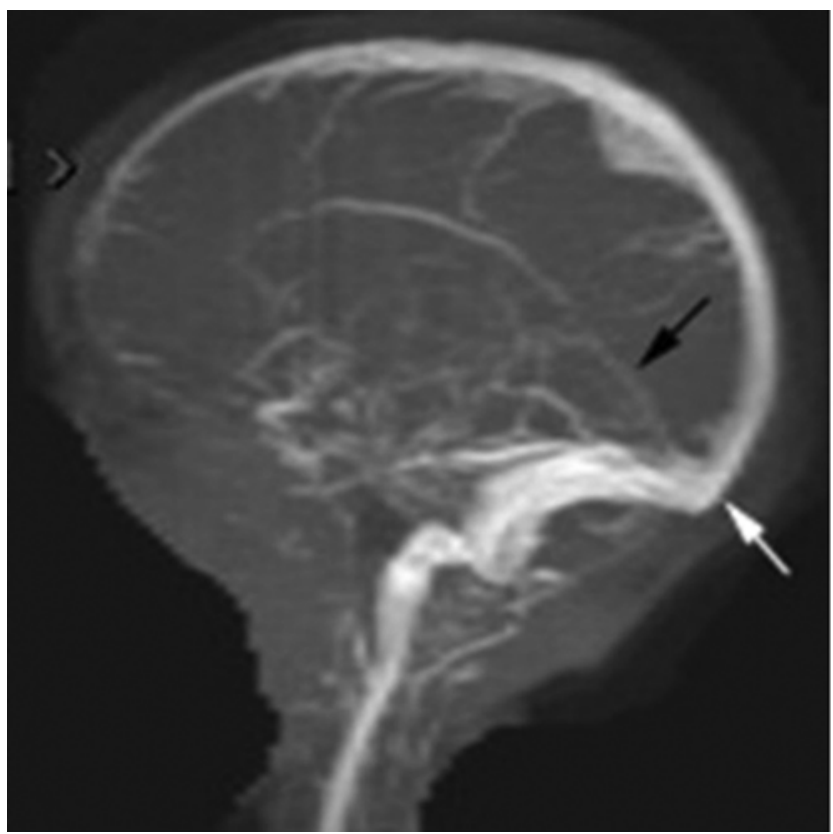

FIG. 4. Follow-up MR venogram showing spontaneous thrombosis or regression of the previously dilated vein of Galen, with normal-caliber straight sinus (black arrow) and transverse/sagittal sinus confluence (white arrow). 
nounced choroidal vessels (Fig. 4). Follow-up ECG no longer showed reversal of blood flow at the aortic arch during diastole.

\section{Discussion}

Vein of Galen malformations arise as a result of direct arteriovenous communications between the arterial network and the median prosencephalic vein during the 6th and 11th week of intrauterine life. ${ }^{25}$ The widespread use of routine antenatal ultrasound has enabled the detection of VGMs in the third trimester of pregnancy, allowing the physician and surgical teams adequate time to develop a management plan. Additionally, antenatal ultrasound has the ability to detect hydrocephalus and cardiac dysfunction in the fetus.

The clinical presentation of a patient with a VGM depends highly on the severity of shunting through the fistula. ${ }^{12}$ Neonates characteristically present with highoutput congestive cardiac failure. Depending on the size of shunt and adequacy of venous drainage, the cardiac manifestations can range from asymptomatic cardiomegaly to severe cardiac failure refractory to medical management. During intrauterine life, the low resistance of the placental circulation competes with the cerebral arteriovenous shunt. Therefore, blood flow through the shunt is not as great as it is after birth. In utero, the left ventricle supplies the fistula while the right ventricle supplies the placenta and the rest of the body. Consequently, the circulatory overload is shared between the two ventricles, which work in parallel. ${ }^{13}$

After birth, however, each ventricle supplies the entire circulation in series. The burden on each ventricle increases and cardiac failure ensues. Exclusion of the low-resistance placental circulation results in an abrupt increase in flow across the fistula-as much as $80 \%$ of the left ventricular output may be supplied to the brain in severe cases. The increased flow in return results in pulmonary hypertension. Furthermore, large arteriovenous shunts significantly reduce the diastolic pressure within the aorta, causing reduced coronary artery flow, thereby promoting myocardial ischemia. ${ }^{5,13,23}$ As seen in our patient on ECG, the resistance through the malformation may be low enough to induce a steal phenomenon manifesting as a reversal of aortic flow during diastole.

Based on a review of all the published cases in the

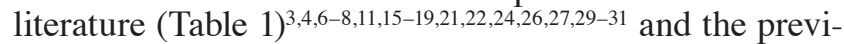
ous work of others, we found that it is still not certain why some VGMs spontaneously thrombose and others do not. Clinical outcomes in these patients are diverse, ranging from death to an asymptomatic course. However, there are certain characteristics shared among patients with spontaneously thrombosed malformations that may provide some insight. Formation "of "mixed" blood clots of various ages with hypo- and hyperdense components on noncontrast CT scanning was evident in many of these patients. Also often demonstrated was a target sign on contrast-enhanced CT scans or CT venograms, described as a central hypodensity (luminal thrombus), surrounded by a crescent of hyperdensity (flowing blood). As mentioned by Nikas et al., ${ }^{21}$ the formation of blood clots within the malformation diminishes the blood flow and intraaneurysmal pressure, and the aneurysm vanishes progressively.

Pathological evidence also suggest that there is what is described as "vintage" layering of the clot in these spontaneously thrombosed lesions..$^{20}$ Lazar et al. ${ }^{20}$ reported the oldest clot was found furthest from the center of the aneurysm along the wall posteriorly and laterally. The youngest layers of the clot were present toward the center and anteriorly, close to the origin of the aneurysm.

On imaging, many patients also exhibited a crescentic rim of calcification, ${ }^{2}$ but this was not predictive of thrombosis, as a comparable percentage of patients without thrombosis also had calcification (14\%). ${ }^{26}$ The degree of calcification can also depend on the degree of arteriovenous shunting. If a patient has a high degree of arteriovenous shunting with a large number of feeders entering the dilated drainage sac, the likelihood of progressive steal of blood from the brain parenchyma is high. Subsequently, patient will develop progressive brain atrophy and calcifications within a relatively short period of time. However, calcifications are rarely seen before the age of 15 years, and complete calcification of the aneurysm sac is rare. ${ }^{3}$

On angiography, as previously reported in several patients, one observes low flow or stasis of contrast media in the venous sac, with some degree of venous outflow obstruction, which may contribute to thrombosis. As described in animal studies, there may also be increased flow pressure and congestion on the venous side leading to progressive myointimal proliferation, with hypertrophy of the wall of the vein of Galen, resulting in gradual venous thrombosis. ${ }^{1}$

Of the 2 types of VGMs - namely, choroidal and mural-the latter is characterized by a lower flow state and presumably having a higher possibility of thrombosis. The choroidal type is characterized by multiple feeders from the choroidal arteries and other deep midbrain arteries that converge on a fistula site at the anterior aspect of the median vein. The mural type is characterized by a fistula in the wall of the median prosencephalic vein, often located laterally. They typically have fewer feeding arteries and do not have a complex arterial maze. However, our patient had a high-flow choroidal-type malformation, yet spontaneous thrombosis occurred. Consequently, the reasons behind thrombosis of VGMs must be multifactorial.

Other factors mentioned in the literature leading to thrombosis include the following: 1) mass effect of adjacent or intraaneurysmal clot, 2) posthemorrhagic edema, 3) vascular spasm, and 4) regressive changes in the vessel walls. ${ }^{21}$ One patient was believed to have experienced a thrombosis due to contrast medium following angiography. Nonionic low-osmolar contrast medium can affect platelet activation, red blood cell aggregation, and endothelial integrity. ${ }^{16}$ However, this was an isolated case and further validation of the hypothesis is needed.

In our case, it is difficult to provide a concrete explanation of how the malformation thrombosed or spontaneously regressed. As already mentioned, our patient had a high-flow choroidal malformation, which tend not to thrombose. Over time, high-flow arteriovenous shunts do 
TABLE 1: Summary of cases of thrombosed VGMs*

\begin{tabular}{|c|c|c|c|c|c|}
\hline Authors \& Year & $\begin{array}{l}\text { Age (at presen- } \\
\text { tation), Sex }\end{array}$ & History \& Presentation & $\begin{array}{l}\text { Unique Imaging } \\
\text { Findings (modality) }\end{array}$ & Treatment & Outcome \\
\hline Gold et al., 1964 & 6 mos, $\mathrm{F}$ & $\begin{array}{l}\text { hydrocephalus, irritability, } \\
\text { lethargy }\end{array}$ & none & conservative & death \\
\hline Heinz et al.,1968 & 25 wks, M & $\begin{array}{l}\text { irritability, lethargy, hemi- } \\
\text { paresis, increased ICP, } \\
\text { hydrocephalus }\end{array}$ & none & $\begin{array}{l}\text { aneurysm exci- } \\
\text { sion }\end{array}$ & $\begin{array}{l}\text { postop: decerebrate postur- } \\
\text { ing; 6-mo follow-up: regainec } \\
\text { strength, alert, sociable }\end{array}$ \\
\hline Weir et al., 1968 & $8 \mathrm{yrs}, \mathrm{M}$ & $\begin{array}{l}\text { drowsiness, irritability, } \\
\text { seizure, hydrocephalus }\end{array}$ & calcification (x-ray) & $\begin{array}{l}\text { VA shunt, aneu- } \\
\text { rysm excision }\end{array}$ & $\begin{array}{l}\text { stormy course, minimal head } \\
\text { control, only appeared to } \\
\text { follow bright lights, moving } \\
\text { all extremities }\end{array}$ \\
\hline Jamieson, 1971 & $15 \mathrm{yrs}, \mathrm{F}$ & NA & calcification (x-ray) & $\begin{array}{l}\text { aneurysm exci- } \\
\text { sion }\end{array}$ & NA \\
\hline $\begin{array}{l}\text { Siqueira \& Mur- } \\
\text { ray, } 1972\end{array}$ & $30 \mathrm{yrs}, \mathrm{F}$ & $\begin{array}{l}\text { progressive spasticity, } \\
\text { hydrocephalus }\end{array}$ & calcification (x-ray) & $\begin{array}{l}\text { aneurysm exci- } \\
\text { sion }\end{array}$ & $\begin{array}{l}\text { can manage activities of daily } \\
\text { living }\end{array}$ \\
\hline Lazar, 1974 & $11 \mathrm{mos}, \mathrm{F}$ & $\begin{array}{l}\text { drowsiness, irritability, } \\
\text { hydrocephalus }\end{array}$ & calcifications (x-ray) & $\begin{array}{l}\text { VP shunt, aneu- } \\
\text { rysm excision }\end{array}$ & $\begin{array}{l}\text { initial stormy course, opistho- } \\
\text { tonic, but improving }\end{array}$ \\
\hline Six et al., 1980 & $3.5 \mathrm{yrs}, \mathrm{M}$ & $\begin{array}{l}\text { drowsiness, irritability, } \\
\text { hydrocephalus }\end{array}$ & "target sign" (CT \& angiogram) & $\begin{array}{l}\text { resection of } \\
\text { thrombus }\end{array}$ & asymptomatic \\
\hline \multicolumn{6}{|l|}{$\begin{array}{l}\text { Diebler et al., } \\
1981\end{array}$} \\
\hline Case 1 & $3 \mathrm{mos}, \mathrm{NA}$ & hydrocephalus, SAH & thrombosis at diagnosis & conservative & $\begin{array}{l}\text { normal mental development, } \\
\text { asymptomatic }\end{array}$ \\
\hline Case 2 & 3 mos, NA & hydrocephalus & none & conservative & vegetative state \\
\hline Case 3 & 2 mos, NA & tonic seizures & none & conservative & $\begin{array}{l}\text { normal mental development, } \\
\text { asymptomatic }\end{array}$ \\
\hline Olin et al., 1982 & $4.5 \mathrm{yrs}, \mathrm{F}$ & $\begin{array}{l}\text { headache, nausea, vomiting, } \\
\text { lethargy }\end{array}$ & $\begin{array}{l}\text { calcification (CT), "target sign" } \\
\text { (CT) }\end{array}$ & VP shunt & asymptomatic \\
\hline $\begin{array}{l}\text { Lasjaunias et al., } \\
\text { 1984-1994 }\end{array}$ & $\begin{array}{l}5 \text { different } \\
\text { children } \\
\text { (unspecified } \\
\text { ages), NA }\end{array}$ & NA & NA & NA & $\begin{array}{l}2 \text { of } 5 \text { children neurologically } \\
\text { intact }\end{array}$ \\
\hline $\begin{array}{l}\text { Whitaker et al., } \\
1987\end{array}$ & 6 mos, $\mathrm{F}$ & hydrocephalus & $\begin{array}{l}\text { partial thrombosis at diagno- } \\
\text { sis, calcification, hypoin- } \\
\text { tense/hyperintense clot (CT) }\end{array}$ & VP shunt & doing well \\
\hline $\begin{array}{l}\text { Gangemi et al., } \\
1988\end{array}$ & $8 \mathrm{mos}, \mathrm{M}$ & $\begin{array}{l}\text { hydrocephalus, vomiting, } \\
\text { lethargy }\end{array}$ & $\begin{array}{l}\text { low-flow shunt (4-vessel } \\
\text { angiography), hypointense } \\
\text { w/ hyperintense rim (CT) }\end{array}$ & VP shunt & asymptomatic \\
\hline $\begin{array}{l}\text { Collins \& Fisher, } \\
1990\end{array}$ & $20 \mathrm{yrs}, \mathrm{M}$ & $\begin{array}{l}\text { headache, fever, meningeal } \\
\text { signs, Parinaud syndrome }\end{array}$ & none & conservative & $\begin{array}{l}\text { rt thalamic \& intraventricular } \\
\text { hemorrhage }\end{array}$ \\
\hline $\begin{array}{l}\text { Quek \& Chang, } \\
1997\end{array}$ & $40 \mathrm{yrs}, \mathrm{F}$ & confusion, disorientation & partial thrombosis at diagnosis & conservative & $\begin{array}{l}\text { no significant neurological } \\
\text { deficit }\end{array}$ \\
\hline $\begin{array}{l}\text { Chiang et } \\
\text { al.,1999 }\end{array}$ & 36 wks, F & asymptomatic & none & conservative & $\begin{array}{l}\text { meeting all developmental } \\
\text { milestones }\end{array}$ \\
\hline \multicolumn{6}{|l|}{ Nikas et al., 1999} \\
\hline Case 1 & $5 \mathrm{yrs}, \mathrm{M}$ & hydrocephalus & none & VP shunt & $\begin{array}{l}\text { neurological exam normal, } \\
\text { active in school \& sports }\end{array}$ \\
\hline Case 2 & 39 wks, NA & asymptomatic & $\begin{array}{l}\text { partial thrombosis varix in } \\
\text { region of vein of Galen (MR) }\end{array}$ & conservative & $\begin{array}{l}\text { neurological exam normal, } \\
\text { surpassed peers in develop- } \\
\text { mental milestones }\end{array}$ \\
\hline $\begin{array}{l}\text { Konus et al., } \\
2000\end{array}$ & $5 \mathrm{yrs}, \mathrm{M}$ & macrocephaly & $\begin{array}{l}\text { mural-type; thrombosis follow- } \\
\text { ing diagnostic angiography }\end{array}$ & conservative & $\begin{array}{l}\text { seizure attack } 2 \text { yrs after } \\
\text { thrombosis }\end{array}$ \\
\hline
\end{tabular}

(continued) 


\section{Vein of Galen malformation}

TABLE 1: Summary of cases of thrombosed VGMs* (continued)

\begin{tabular}{|c|c|c|c|c|c|}
\hline Authors \& Year & $\begin{array}{l}\text { Age (at presen- } \\
\text { tation), Sex }\end{array}$ & History \& Presentation & $\begin{array}{l}\text { Unique Imaging } \\
\text { Findings (modality) }\end{array}$ & Treatment & Outcome \\
\hline $\begin{array}{l}\text { Kuzeyli et al., } \\
2004\end{array}$ & $6 \mathrm{mos}, \mathrm{M}$ & $\begin{array}{l}\text { nausea, vomiting, irritabil- } \\
\text { ity, convulsive attacks, } \\
\text { hydrocephalus }\end{array}$ & $\begin{array}{l}\text { lesion hyperintense w/ } \\
\text { hypointense peripheral rim } \\
\text { (T2 MRI) }\end{array}$ & VP shunt & $\begin{array}{l}\text { normal physical \& neurologi- } \\
\text { cal exam }\end{array}$ \\
\hline $\begin{array}{l}\text { Vijayaraghavan } \\
\text { et al., } 2006\end{array}$ & $\begin{array}{l}21 \text { wks (fetus), } \\
\text { NA }\end{array}$ & $\begin{array}{l}\text { dilated neck vessels, cardio- } \\
\text { megaly \& minimal ascites }\end{array}$ & $\begin{array}{l}\text { thrombosis prenatally (ultra- } \\
\text { sound) }\end{array}$ & fetus aborted & fetus aborted \\
\hline present case & 39 wks, F & asymptomatic & none & conservative & $\begin{array}{l}\text { meeting all developmental } \\
\text { milestones }\end{array}$ \\
\hline
\end{tabular}

* ICP = intracranial pressure; $\mathrm{NA}=$ not available; $\mathrm{SAH}=$ subarachnoid hemorrhage; $\mathrm{VA}=$ ventriculoatrial; VP = ventriculoperitoneal.

lead to venous wall changes, such as venous aneurysms, venous stenosis, and other venopathies, due to the venous hypertension. It is speculated that in our patient such a venous outflow stenosis developed chronically, over time, and that this gradually shut down the arteriovenous fistula. More rapid, acute, spontaneous thrombosis is also possible; however, this scenario is more likely to result in spontaneous catastrophic hemorrhage.

Among demographic factors, neither age nor sex has been shown to be predictive of thrombosis. Patients in the literature have ranged from fetuses (21 weeks' gestation) to adult age (40 years), with a ratio of roughly 50:50 male/ female. The most common presentation was hydrocephalus and macrocephaly, with $33 \%$ of the patients receiving shunts. None of the patients presented with any signs or symptoms of a high-flow shunt, such as congestive cardiac failure. Thirty-percent of patients underwent direct excision of the thrombus. Complete surgical elimination of the lesion is rarely achieved, and after the early 1980s none of the patients were treated with direct excision. Instead, they underwent shunt implantation or conservative management. Although ventricular shunt surgery may worsen cerebral venous hypertension in this patient population, most of the shunt-treated patients had good clinical outcomes. Overall, $70 \%$ of patients had good to excellent clinical outcomes (Table 1).

Angiography is the gold standard for evaluation of VGMs. On antenatal ultrasound the lesions present as a supratentorial sonolucent mass located posterior or slightly lateral to the third ventricle. The sagittal sinus is reported as dilated in most cases. The turbulent vascular flow in the cystic structure detected by pulsed and color Doppler ultrasonography enables the diagnosis of a VGM and helps distinguish it from other abnormal intracranial midline structures, such as arachnoid or porencephalic cysts, Dandy-Walker malformations, or intracerebral hematomas. ${ }^{29}$ Additionally, it can help determine the presence of hydrocephalus and assess the status of the fetal cardiovascular system. Postnatally, ultrasound can be used to demonstrate hemodynamic changes associated with the malformation, including assessing the status of the shunt on serial studies. ${ }^{9}$

The management of VGMs has evolved since the time of Balance in $1905^{10}$ who used bilateral internal carotid artery occlusion to treat these lesions. Untreated VGMs have a poor prognosis. ${ }^{14,29}$ The degree of shunting deter- mines the overall prognosis and management. High-flow shunts across the malformation can lead to high-output congestive heart failure. In these cases, rapid and aggressive medical management is required. Medical management can postpone endovascular or surgical intervention until the child is about 5-6 months old, at which time the child is more stable and can endure the course of a procedure. Treatment at the age of 5 months balances the benefits of safe embolization against the risk of cerebral damage. Imaging evidence of encephalomalacia is thus considered a relative contraindication to endovascular therapy. ${ }^{9,29}$ Patients refractory to medical therapy require emergency endovascular embolization.

In asymptomatic children, we recommend follow-up imaging (color transcranial Doppler ultrasonography) every 3 months. If the children are meeting their developmental milestones, we recommend follow-up MR imaging at 1 year. It is important to have yearly imaging even in asymptomatic children, because the degree of shunting with the malformation may change over time, leading to strokes and venous infarcts. We typically do not recommend serial CT or CT angiography because it may be detrimental to the developing brain due to the amount of radiation. In patients who are symptomatic, early endovascular treatment is indicated. In asymptomatic patients, we frequently will recommend endovascular treatment at 1-2 years of age because chronic arteriovenous shunting in the brain predisposes the patient to developmental delay, seizures, venous infarction, and cerebral hemorrhage.

\section{Conclusions}

Vein of Galen malformations are rare vascular anomalies of the intracranial circulation. Even rarer is the reported occurrence of spontaneously thrombosed VGMs. Based on our review of the literature, factors predictive of spontaneous thromboses included the following: 1) evidence of mixed clot or a target sign on imaging, 2) venous stasis and venous outflow congestion, 3) mass effect of adjacent or intraaneurysmal clot, 4) posthemorrhagic edema, 5) vascular spasm, and 6) regressive changes in the vessel walls. Although the low-flow mural-type malformation is thought to have a higher rate of thrombosis, in our case the patient presented with a high-flow choroidal-type anomaly, suggesting that thrombosis of 


\section{P. Moftakhar et al.}

VGMs is multifactorial. Neither age nor sex was predictive of thrombosis. Children presenting with congestive heart failure should be approached with aggressive medical therapy and subsequent endovascular embolization. Asymptomatic patients can be treated with expectant medical therapy and serial angiography, with the possibility of spontaneous thrombosis. Cardiac ECG is a noninvasive modality that can assist in following intracranial arteriovenous shunting. Future molecular and physiological studies can help elucidate the reasons behind spontaneous thrombosis of these malformations.

\section{Disclaimer}

The authors report no conflict of interest concerning the materials or methods used in this study or the findings specified in this paper.

\section{References}

1. Brunelle F: Arteriovenous malformation of the vein of Galen in children. Pediatr Radiol 27:501-513, 1997

2. Chapman S, Hockley AD: Calcification of an aneurysm of the vein of Galen. Pediatr Radiol 19:541-542, 1989

3. Chiang V, Awad I, Berenstein A, Scott M, Spetzler R, Alexander MJ: Neonatal galenic arteriovenous malformation. Neurosurgery 44:847-854, 1999

4. Collins JJ, Fisher WS III: Vein of Galen aneurysm presenting with recurrent aseptic meningitis and subsequent spontaneous thrombosis. Surg Neurol 33:325-328, 1990

5. Crawford JM, Rossitch E Jr, Oakes WJ, Alexander E 3rd: Arteriovenous malformation of the great vein of Galen associated with patent ductus arteriosus. Childs Nerv Syst 6:18-22, 1990

6. Diebler C, Dulac O, Renier D, Ernest C, Lalande G: Aneurysms of the vein of Galen in infants aged 2 to 15 months. Diagnosis and natural evolution. Neuroradiology 21:185-197, 1981

7. Gangemi M, Maiuri F, Donati PA, Ianconetta G: Spontaneous thrombosis of aneurysm of the vein of Galen. Acta Neurol (Napoli) 10:113-118, 1988

8. Gold AP, Ransohoff JR, Carter S: Vein of Galen malformation. Acta Neurol Scand 40 (111 Suppl):5, 1964

9. Gupta AK, Varma DR: Vein of Galen malformations. Review Neurol India 52:43-53, 2004

10. Hamilton MG, Herman JM, Khayata MH, Spetzler FR: Aneurysms of the vein of Galen, in Youmans JR (ed): Neurological Surgery. Philadelphia: Saunders, 1996, vol 2, pp 1491-1510

11. Heinz ER, Schwartz JF, Sears RA: Thrombosis in vein of Galen malformation. Br J Radiol 41:424-428, 1968

12. Hoffman HJ: Direct surgical treatment of vein of Galen malformation, in Rengachary SS, Wilkins RH (eds): Neurosurgical Operative Atlas, Vol 1. Baltimore: Williams \& Wilkins, 1991, pp 205-214

13. Hoffman HJ: Malformations of the vein of Galen, in Edwards MSB, Hoffman HJ (eds): Current Neurosurgical Practice: Cerebral Vascular Disease in Children and Adolescents. Baltimore: Williams \& Wilkins, 1989, pp 239-246

14. Hoffman HJ, Chuang S, Hendrick EB, Humphreys RP: Aneurysms of the vein of Galen. Experience at The Hospital for Sick Children, Toronto. J Neurosurg 57:316-322, 1982
15. Jamieson KG: Excision of pineal tumors. J Neurosurg 35: 550-553, 1971

16. Konus OL, Ilgit ET, Ozdemir A, Onal B: Spontaneous thrombosis of a vein of Galen aneurysmal malformation: possible effects of contrast media. Eur Radiol 10:1456-1458, 2000

17. Kuzeyli K, Cakir E, Karaarsian G, Ahmetoglu A, Peksoylu B, Yazar U, et al: Spontaneous thrombosis of vein of Galen aneurismal malformation after ventriculoperitoneal shunting. J Clin Neurosci 11:439-442, 2004

18. Lasjaunias P: Vein of Galen aneursymal malformation, in Vascular Diseases in Neonates, Infants and Children. Berlin: Springer-Verlag, 1997, pp 67-202

19. Lasjaunias P, Rodesch G, Terbrugge K, Provost P, Devictor D, Comoy J, et al: Vein of Galen aneurysmal malformations: report of 36 cases managed between 1982 and 1988. Acta Neurochir (Wien) 99:26-37, 1989

20. Lazar ML: Vein of Galen aneurysm: successful excision of a completely thrombosed aneurysm in an infant. Surg Neurol 2:22-24, 1974

21. Nikas DC, Proctor MR, Scott RM: Spontaneous thrombosis of vein of Galen aneurysmal malformation. Pediatr Neurosurg 31:33-39, 1999

22. Olin MS, Eltomey AA, Dunsmore RH, Roberts MP: Thrombosed vein of Galen aneurysm. Neurosurgery 10:258-262, 1982

23. Pellegrino PA, Milanesi O, Saia OS, Carollo C: Congestive heart failure secondary to cerebral arterio-venous fistula. Childs Nerv Syst 3:141-144, 1987

24. Quek ST, Chang SK: Clinics in diagnostic imaging. Singapore Med J 38:449-452, 1997

25. Raybaud CA, Strother CM, Hald JK: Aneurysms of the vein of Galen: embryonic considerations and anatomical features relating to the pathogenesis of the malformation. Neuroradiology 31:109-128, 1989

26. Siqueira EB, Murray KJ: Calcified aneurysms of the vein of Galen: report of a presumed case and review of the literature. Neurochirurgia (Stuttg) 15:106-112, 1972

27. Six EG, Cowley R, Kelly DL, Laster DW: Thrombosed aneurysm of the vein of Galen. Neurosurgery 7:274-278, 1980

28. Steinheil SO: Uber einen Fall von Varex Aneurysmaticus im Bereich der Gehirngefasse. Wurzburg: Fromme, 1895

29. Vijayaraghavan SB, Vijay S, Kala MR, Neha D: Prenatal diagnosis of thrombosed aneurysm of vein of Galen. Ultrasound Obstet Gynecol 27:81-83, 2006

30. Weir BKA, Allen PBR, Miller JDR: Excision of thrombosed vein of Galen aneurysm in an infant. Case report. J Neurosurg 29:619-622, 1968

31. Whitaker JB, Latack JT, Venes JL: Spontaneous thrombosis of a vein of Galen aneurysm. AJNR Am J Neuroradiol 8:1134-1136, 1987

Manuscript submitted July 15, 2009.

Accepted August 27, 2009.

Address correspondence to: Michael J. Alexander, M.D., CedarsSinai Neurovascular Center, Cedars-Sinai Medical Center, 8631 West Third Street, Suite 800E, Los Angeles, California 90048 email: michael.alexander@cshs.org. 